\title{
Cardiac Muscle Involvement in Muscle Disorders
}

Key words: cardiomyopathy, atrioventricular block, muscle diseases, Emery-Dreifuss muscular dystrophy

Cardiac muscle involvement is not a rare complication in muscle disorders as is most commonly seen in muscular dystrophies. Hypertrophic and/or dilated cardiomyopathy progresses in parallel with disease progression in most of patients with Duchenne and Becker muscular dystrophies, though cardiac failure may precede skeletal muscle symptoms, especially in Becker form. Cardiac muscle involvement is also commonly seen in metabolic myopathies including glycogen storage diseases and mitochondrial disorders.

In this issue of the Journal (1), Ohkubo et al report an interesting family with myopathy and atrioventricular (AV) block.

See also $\mathrm{p} 856$.

Although the AV block has been described in many disorders, the most common diseases are Emery-Dreifuss muscular dystrophy, and chronic progressive external ophthalmoplegia (Kearns-Sayre syndrome), the most common form of mitochondrial diseases. Cardiac pacemaker implantation is frequently necessary for patients with the above two diseases.

Emery-Dreifuss muscular dystrophy was first described as an X-linked recessively inherited disorder characterized clinically by early onset of ankle and elbow joint contractures with occasional paraspinal muscle involvement (rigid spine), but with mild slowly progressive muscle weakness in humeropelvic distribution $(2,3)$. Muscle biopsies exhibit myopathic changes with occasional muscle fiber necrosis and regeneration, representing slowly progressive muscular dystrophic changes. The gene was mapped to chromosome Xq28 (4) and the gene product of emerin was proved to localize at the nuclear membrane (5). Patients have no immunoreactivity to an emerin antibody which is a diagnostic finding for this disease.

Another form of Emery-Dreifuss muscular dystrophy is inherited through an autosomal dominant trait $(6,7)$. The overall symptoms are similar to those seen in the $\mathrm{X}$-linked form. The gene was mapped to chromosome 1q11-q23, and mutations were found in the gene encoding lamins $\mathrm{A}$ and $\mathrm{C}$, which are proteins of the nuclear lamina produced by alternative splicing (8). However, the nuclear membrane in muscle biopsies from patients is positively stained with anti-lamin $\mathrm{A} / \mathrm{C}$ antibody.

Although Ohkubo et al (1) excluded the possibility of autosomal dominant Emery -Dreifuss muscular dystrophy in the present familial patients, the clinical and pathologic findings in their family are not that different from the disease. Further genetic analysis on this family will provide additional knowledge for understanding the pathogenesis of AV block in relation to Emery-Dreifuss muscular dystrophy.

Ikuya NonAKA, MD National Center of Neurology and Psychiatry, Kodaira, Tokyo 187-8551

\section{References}

1) Ohkubo R, Nakagawa M, Higuchi I, et al. Familial skeletal myopathy with atrioventricular block. Intern Med 38: 856-860, 1999.

2) Emery AE. X-linked muscular dystrophy with early contractures and cardiomyopathy (Emery-Dreifuss type). Clin Genet 32: 360-367, 1987.

3) Tsuchiya Y, Arahata K. Emery-Dreifuss syndrome. Curr Opin Neurol 10: 421-425, 1997.

4) Bione S, Maestrini E, Rivella S, et al. Identification of a novel X-linked gene responsible for Emery-Dreifuss muscular dystrophy. Nat Genet 8: 323-327, 1994.

5) Nagano A, Koga R, Ogawa M, et al. Emerin deficiency at the nuclear membrane in patients with Emery-Dreifuss muscular dystrophy. Nat Genet 12: 254-259, 1996

6) Fenichel GM, Sul YC, Kilroy AW, Blouin R. An autosomal-dominant dystrophy with humeropelvic distribution and cardiomyopathy. Neurology 32: 1399-1401, 1982.

7) Miller RG, Layzer RB, Mellenthin MA, Golabi M, Francoz RA, Mall JC. Emery-Dreifuss muscular dystrophy with autosomal dominant transmission. Neurology 35: 1230-1233, 1985.

8) Bonne G, Di Barletta MR, Varnous S, et al. Mutations in the gene encoding lamin $\mathrm{A} / \mathrm{C}$ cause autosomal dominant Emery-Dreifuss muscular dystrophy. Nat Genet 21: 285-288, 1999. 